\title{
Supporting Patient Behavior Change: Approaches Used by Primary Care Clinicians Whose Patients Have an Increase in Activation Levels
}

Jessica Greene, $P b D^{1}$

Judith H. Hibbard, DrPH ${ }^{2}$

Carmen Alvarez, PbD, RN, NP-C, $\mathrm{CNM}^{3}$

Valerie Overton, DNP

${ }^{1}$ School of Nursing, George Washington University, Washington, DC

${ }^{2}$ ISE Health Policy Group, University of Oregon, Eugene, Oregon

${ }^{3}$ School of Nursing, Department of Community-Public Health, Johns Hopkins University, Baltimore, Maryland

${ }^{4}$ Fairview Medical Group, Minneapolis, Minnesota
Conflicts of interest: Judith Hibbard is a consultant to and equity stakebolder in Insignia Health. The other authors bave no conflicts to report.

\section{CORRESPONDING AUTHOR}

Jessica Greene, PhD George Washington University

2030 M St NW, Ste 300

Washington, DC 20036

jessgreene@gwu.edu

\begin{abstract}
PURPOSE We aimed to identify the strategies used to support patient behavior change by clinicians whose patients had an increase in patient activation.

METHODS This mixed methods study was conducted in collaboration with Fairview Health Services, a Pioneer Accountable Care Organization. We aggregated data on the change in patient activation measure (PAM) score for 7,144 patients to the primary care clinician level. We conducted in-depth interviews with 10 clinicians whose patients' score increases were among the highest and 10 whose patients' score changes were among the lowest. Transcripts of the interviews were analyzed to identify key strategies that differentiated the clinicians whose patients had top PAM change scores.
\end{abstract}

RESULTS Clinicians whose patients had relatively large activation increases reported using 5 key strategies to support patient behavior change (mean $=3.9$ strategies): emphasizing patient ownership; partnering with patients; identifying small steps; scheduling frequent follow-up visits to cheer successes, problem solve, or both; and showing caring and concern for patients. Clinicians whose patients had lesser change in activation were far less likely to describe using these approaches (mean $=1.3$ strategies). Most clinicians, regardless of group, reported developing their own approach to support patient behavior change. Those whose patients showed high activation change reported spending more time with patients on counseling and education than did those whose patients showed less improvement in activation.

CONCLUSIONS Clinicians vary in the strategies they use to promote behavior change and in the time spent with patients on such activities. The 5 key strategies used by clinicians with high patient activation change are promising approaches to supporting patient behavior change that should be tested in a larger sample of clinicians to validate their effectiveness.

Ann Fam Med 2016;14:148-154. doi:10.1370/afm.1904.

\section{INTRODUCTION}

Through policies such as pay for performance and public reporting of clinicians' quality of care, clinicians are increasingly responsible for their patients' care outcomes. ${ }^{1-4}$ Yet, for health outcomes to improve, patients must do their part, following through on treatment regimens and making recommended lifestyle changes. ${ }^{5.7}$ Given the key role that patients play in determining health outcomes, policy makers have made patient engagement and patient activation a major focus, including embedding approaches for increasing engagement in the Patient Protection and Affordable Care Act. ${ }^{8,9}$

Patient activation, which is defined as having the knowledge, confidence, and skills to take care of one's health and health care, has been shown to be associated with a broad range of health-related outcomes, including better self-management and clinical indicators, fewer hospitalizations, and lower health care costs. ${ }^{10-20}$ Recently, studies have demonstrated 
that one's activation level predicts outcomes over several years, and that when activation levels change, many outcomes change in the expected direction. ${ }^{21,22}$

Although the evidence base for the relationship between patient activation and health outcomes has developed substantially, less is known about how patients' activation levels can be increased. Studies have found that patient education and empowerment efforts, such as the Stanford Chronic Disease Self-Management Program and coaching with motivational interviewing, increase activation. ${ }^{23-31}$ Very little research, however, has examined the clinician role in supporting patient activation. Given clinicians' key potential impact on patient behavior, this is an important area for investigation.

Related research has shown, for example, that clinicians' use of motivational interviewing and other communication-based behavior change techniques can improve patients' self-management behaviors and health outcomes. ${ }^{32,33}$ Several studies have found that physician behaviors, such as showing empathy and not being verbally dominant, are associated with increases in patients' understanding of their condition and ability to manage their illness. ${ }^{34-36}$ Also, patients' assessment of clinician support of the chronic care model has been associated with higher levels of self-management. ${ }^{37-39}$

Research to date has not examined whether clinicians' behaviors influence patients' level of activation, however. That is, although some of these behaviors may be intended to engage patients in their own care, for example, the sharing of the medical record or asking patients to state preferences, it is unclear which if any of these behaviors result in an overall increased capacity for patients to self-manage (or to become more activated). In addition, prior studies have not typically examined the constellation of strategies used by clinicians who have proven that they are effective in this arena. We therefore undertook a study not only to help elucidate the behaviors that are effective in supporting greater activation, but also to help elaborate the potential causal chain that links these behaviors with better outcomes.

\section{METHODS}

We used a modified version of the positive deviance approach, which is a mixed methods approach premised on the notion that solutions to challenging problems already exist, have been developed by innovative individuals (or groups) or "positive deviants," and can be discerned to help others improve outcomes. ${ }^{40,41}$ The methodology was developed to address health problems in developing countries, but has been recently used in the United States to identify effective approaches to improving quality of care. ${ }^{40,42-48}$ Positive deviants are identified using established performance measures, and then qualitative interviews are conducted with these individuals to develop hypotheses about their distinctive strategies. Some researchers additionally conduct qualitative research with low or average performers, as was done in this study, so that positive deviants' strategies can be distinguished from those used by others. ${ }^{42,43,45}$

This study was conducted in collaboration with Fairview Health Services, a Pioneer Accountable Care Organization in Minnesota. Since mid-2010, Fairview has routinely had primary care patients complete the 13 -item patient activation measure (PAM). ${ }^{9}$ The PAM has an interval-level, Guttman-like scale; possible scores range from 1 to 100, with higher scores indicating greater patient activation. Prior studies have found a difference of at least 5 points to be meaningful. ${ }^{49-51}$ Our modified positive deviance approach used data on the change in PAM scores to identify those primary care clinicians whose patients' scores increased the most and the least. We then conducted in-depth interviews with these positive and negative deviants, to distill the differentiating strategies used by top performers to support self-management and behavior change.

We began with a panel of 7,144 patients who had 2 PAM scores between 2010 and 2012, and whose baseline score was not in the highest of 4 levels of scores. We aggregated the panel to the clinician level, retaining 54 clinicians who had 40 or more patients with serial PAM scores. We ranked the clinicians based on the change in their patients' scores. We considered the top 15 clinicians based on mean and median change in score ( 9 were on both lists) to be the positive deviants, whom we refer to as the top performers, and the bottom 15 clinicians based on either mean or median change in score (12 were on both lists) to be the negative deviants or bottom performers.

In the fall of 2013, 2 of the authors (J.G. and J.H.H., both social scientists) conducted 20 in-depth interviews, divided between top and bottom performers. All but 2 interviews were conducted face to face. A semistructured protocol was used to explore the strategies clinicians used when it came to the most challenging component of self-management, lifestyle behavior change, as exemplified by quitting smoking or increasing exercise. ${ }^{38}$ The interview guide also explored how the clinicians handled situations when patients did not make recommended behavioral changes and their training in patient behavior change. Interviews lasted approximately 30 minutes, were audio recorded, and were transcribed verbatim.

\section{Data Analysis}

Two of the authors (J.G. and C.A., both social scientists, 1 of whom is also a nurse practitioner) developed 
Table 1. Comparison of Top- and Bottom-Performing Clinicians

\begin{tabular}{|c|c|c|}
\hline Characteristic & $\begin{array}{l}\text { Top-Performing } \\
\text { Clinicians } \\
(n=10)\end{array}$ & $\begin{array}{l}\text { Bottom-Performing } \\
\text { Clinicians } \\
(\mathbf{n}=10)\end{array}$ \\
\hline \multicolumn{3}{|l|}{ Patients $^{a}$} \\
\hline \multicolumn{3}{|l|}{ Change in PAM score } \\
\hline Mean & 7.5 & 3.1 \\
\hline Median & 5.5 & 1.3 \\
\hline Chronic conditions, mean No.b & 0.6 & 0.7 \\
\hline $\begin{array}{l}\text { Emergency department visits, }{ }^{c} \\
\text { mean No. }\end{array}$ & 0.3 & 0.3 \\
\hline Hospitalizations, ${ }^{c}$ mean No. & 0.1 & 0.1 \\
\hline \multicolumn{3}{|l|}{ Clinicians } \\
\hline \multicolumn{3}{|l|}{ Sex } \\
\hline Male, No. & 3 & 7 \\
\hline Female, No. & 7 & 3 \\
\hline \multicolumn{3}{|l|}{ Type of clinician } \\
\hline Family practitioner, No. & 7 & 5 \\
\hline Internist, No. & 1 & 2 \\
\hline Internist/pediatrician, No. & 1 & 2 \\
\hline Nurse practitioner, No. & 1 & 0 \\
\hline Physician assistant, No. & 0 & 1 \\
\hline \multicolumn{3}{|c|}{$\begin{array}{l}\text { PAM = patient activation measure (scores range from } 1 \text { to } 100 \text {, with higher scores indicating } \\
\text { greater activation). }\end{array}$} \\
\hline \multicolumn{3}{|c|}{$\begin{array}{l}\text { a Among those having } 2 \text { PAM scores. } \\
\text { b Diabetes, asthma, hyperlipidemia, chronic obstructive pulmonary disease, coronary artery } \\
\text { disease, congestive heart failure, and depression. } \\
\text { ' At Fairview Health Services in the baseline year. }\end{array}$} \\
\hline
\end{tabular}

a set of thematic codes related to patient support strategies based on a review of several transcripts. The 2 authors independently reviewed each transcript to identify text blocks that related to each code, and the coding was compared and reconciled. Both reviewers believed thematic saturation had been reached. In the text, we have included the clinician number by each quotation (1 to 10 indicate top performers and 11 to 20 indicate bottom performers).

\section{RESULTS}

Table 1 shows the characteristics of the clinicians studied and the changes in PAM scores of their patients. The mean change in score was 7.5 points among the top-performing clinicians interviewed, whereas it was just 3.1 points among the bottom-performing clinicians. The patients of the 2 groups of clinicians were similar in terms of chronic conditions and hospital use. Of note, 2 clinics had both top and bottom performers.

\section{Strategies Used Mainly by Top Performers}

The majority of top performers reported using 5 interrelated strategies described below (mean $=3.9$ strategies) (Table 2 ). The bottom performers were far less likely to report using these approaches (mean $=1.3$ strategies), and when they did endorse the approach, they rarely described it in the same level of detail used by the top performers.

\section{Emphasizing Patient Ownership}

Top performers described emphasizing that it is the patient, not the clinician, who is in charge of the patient's health. A family practitioner (No. 10) explained, "I try to make them be the manager. I give them advice and what I think is the best course of action, I try to make them as responsible as I can... I want them to take ownership."

Several clinicians described their role as that of a "coach," emphasizing the limits of what clinicians can do for patients and the crucial role patients play. One family practice physician (No. 5) described a common conversation that she has with patients: "I'm here to coach you, not to make you better-you make yourself better. I can't do that for you."

\section{Partnering With Patients}

The top performers described working in partnership with patients to create goals, strategize, and problem solve. A family practitioner (No. 6) explained, "I'll ask
Table 2. Behavior Change Strategies Reported by Top- and Bottom-Performing Clinicians

\begin{tabular}{|c|c|c|}
\hline \multirow[b]{2}{*}{ Strategy } & \multicolumn{2}{|c|}{$\begin{array}{c}\text { Clinicians Reporting } \\
\text { Strategy, No. }\end{array}$} \\
\hline & $\begin{array}{l}\text { Top-Performing } \\
\text { Clinicians } \\
(n=10)\end{array}$ & $\begin{array}{c}\text { Bottom-Performing } \\
\text { Clinicians } \\
(n=10)\end{array}$ \\
\hline \multicolumn{3}{|l|}{ Used mainly by top-performing group } \\
\hline Emphasizing patient ownership & 8 & 3 \\
\hline Partnering with patients & 9 & 3 \\
\hline Identifying small steps & 10 & 3 \\
\hline Scheduling frequent follow-up visits & 7 & 3 \\
\hline Showing caring & 5 & 1 \\
\hline \multicolumn{3}{|l|}{ Used by both groups } \\
\hline Reliance on team supports & 10 & 7 \\
\hline \multicolumn{3}{|l|}{ Used mainly by bottom-performing group } \\
\hline $\begin{array}{l}\text { Describing consequences of bad health } \\
\text { behaviors }\end{array}$ & 2 & 8 \\
\hline
\end{tabular}


people, in the first 2 or 3 sentences in the door, how are we going to get you to quit smoking? How can we work together?" Several clinicians explained that working in partnership was essential, because as clinicians, they do not always know what approaches to behavior change are most feasible or appealing to their patients. A family practice physician (No. 10) explained: "I do know them, but I don't know their lives at all outside the clinic."

\section{Identifying Small Steps}

The top performers described working with patients to agree on taking small, feasible steps toward healthier behaviors. Small steps were used to avoid overwhelming patients and to set them up to succeed, so they could take on larger steps in the future. A family practice physician (No. 7) explained, "Trying to get those little improvements is good to get the patient's momentum going, but bombarding them with 10 solutions isn't going to help... I try to meet them where they're at—with baby steps."

Many of the clinicians described working out very detailed steps with patients. For instance, a family practitioner (No. 4) described recommending that patients trying to cut back on smoking count out a number of cigarettes for the day, and hide the rest in their trunk or with a friend. Several clinicians described getting patients to commit to 1 small step as a way to encourage patients reluctant to make behavior change: "If they say, 'I can't do anything to make my life better,' [I'1l say], 'Let's think of something you can do."' (No. 1).

\section{Scheduling Frequent Follow-up}

Top performers described having patients make frequent follow-up visits to support behavior change, so the patients would know they were supported and "the door is always open." Clinicians reported 2 key purposes for frequent follow-up. The first was cheering successes. A family practitioner (No. 1) explained, "When they come in and they've had a success, we celebrate together... I tell them, 'I'm your biggest cheerleader. Whatever you succeed at, I'm going to cheer you on."' The other purpose of frequent follow-up was problem solving. A family practitioner (No. 5) described using the follow-up visits to overcome obstacles: "I ask them, 'Why aren't we successful? What's the problem? What are you finding is keeping you or holding you back?"'

\section{Showing Care}

One-half of the top-performing clinicians described telling their patients how much they cared about them as a way to help support patients in behavior change. As a family practitioner (No. 1) explained: "Most of my patients know I'm very up front and honest. Particu- larly my female patients, they joke with me and say not many men can tell me I'm fat and then see me again... I tell them it's because I care about them and want them to be healthy."

\section{Strategies Used by Both Groups}

Almost all the clinicians described relying on team members, such as hypertension nurses and diabetes educators, to support behavior change. A top-performing family physician (No. 10) explained, "My diabetic educator is essential to my diabetes care... My diabetic educator stays up on the latest, greatest pumps and sensing devices and stuff, I let them manage that stuff."

\section{Strategies Used Mainly by Bottom Performers}

Most bottom-performing clinicians described telling patients the negative health outcomes they can expect if they do not change their unhealthy behaviors. An internist (No. 14) described, "Sometimes you just keep reminding people, 'You're going to kill yourself this way, you gotta' do something."'

\section{Other Differences}

Top performers described counseling and education as a crucial part of their work, taking up at least one-half of their time with patients. In contrast, the bottom performers mostly reported that counseling and education was a smaller component. One family practitioner (No. 14) said, "Maybe not even a third of it with lifestyle stuff. It kind of gets pushed aside because we just don't have time."

The top performers exhibited a more positive attitude toward working with patients on behavior change than bottom performers. For example, a family practitioner (No. 7) described: "I try to be positive about things, smile, being an uplifting person, trying not to be too judgmental. Try to have an open mind going into each visit... you can't go in with a negative attitude." In contrast, several bottom-performing clinicians expressed a sense that they lacked empowerment for working on behavior change. A family practitioner (No. 15) described, "It's unfortunate, some people just seem hopeless-maybe not, but it seems that way."

Interestingly, we noted no difference between the top and bottom performers in their report of prior patient behavior change training. Most reported their approach was based on "trial and error" and "trying to tweak it myself."

\section{DISCUSSION}

We conducted in-depth interviews with 2 groups of primary care clinicians: those whose patients had relatively large increases in activation and those whose 
patients had a comparatively small change. The goal was to identify the distinctive strategies used to support patient behavior change by the exceptional clinicians. We found that most top-performing clinicians used 5 key strategies to support their patients' behavior change: emphasizing patient ownership of their health, partnering with patients, identifying small steps toward change, scheduling frequent follow-up visits so change can be cheered or problems solved, and showing personal care for patients. Bottom-performing clinicians reported using far fewer of these strategies.

Although most of these approaches have been identified in prior research, ${ }^{52-55}$ they have not been combined as a holistic strategy to support patient behavior change or increase patients' activation levels. Our findings also provide new insights on specific approaches, such as clinicians being explicit with patients about expectations with regard to their own role and the role of the patient. This idea of explicit role delineation is not a strategy that is typically included in discussions of best practices. Yet, we know that less activated patients often do not know what their role is in the care process, or believe their role is to be a passive recipient of care. ${ }^{56}$ Moreover, the other 4 strategies embraced by top performers are built on the implicit assumption that clinician and patient are willing to assume roles that are similar to the coach and the coached.

Another important finding is that most clinicians indicated that they had little training in how to support patient behavior change. This finding is not unique to Fairview: in the Duke community physician study, only about one-third of physicians (38\%) reported receiving training in behavioral counseling. ${ }^{57}$ Whereas our top-performing clinicians invested time, effort, and attention to find effective ways to support patient selfmanagement, the bottom-performing clinicians often described not feeling equipped to effectively work on behavior change. Clearly, more self-management support training is needed for clinicians.

These findings should be interpreted in the context of the study's limitations, including availability of data on changes in PAM scores for only a small percentage of Fairview's patients. Another limitation is that the strategies identified were based on clinician report, not observation. Additionally, we conducted the research in a single innovative delivery system, where quality metrics are high, and in a state known for high-quality performance. ${ }^{58}$ Our setting may have less variation across changes in PAM scores than others elsewhere. To validate the study's findings, the relationship between the clinician strategies identified in the study and both patient behavior change and activation change should be tested in a larger sample of clinicians.
Supporting patient self-management represents a paradigm shift for many clinicians. ${ }^{59,60}$ As we see from the results of this study, some clinicians embrace strategies for patient engagement with more enthusiasm than others. From a policy perspective, it is critical that all primary care clinicians support patient selfmanagement and activation. Moreover, it is inefficient for each clinician to use trial and error to find workable strategies. More systematic professional and organizational approaches are needed. Training, incentives, and organization supports are necessary to help clinicians adopt evidence-based approaches to supporting patient self-management and increasing activation levels.

To read or post commentaries in response to this article, see it online at http://www.annfammed.org/content/14/2/148.

Key words: health behavior; behavior change; practice patterns, physicians'; motivation; patient activation; self-management; patient empowerment; mixed methods research; primary care; practice-based research

Submitted May 5, 2015; submitted, revised, November 6, 2015; accepted November 20, 2015.

Funding support: This research was funded by the Gordon and Betty Moore Foundation. The Gordon and Betty Moore Foundation, established in 2000, seeks to advance environmental conservation, patient care, and scientific research. For more information, visit www.moore.org.

\section{References}

1. McDonald R, Roland M. Pay for performance in primary care in England and California: comparison of unintended consequences. Ann Fam Med. 2009;7(2):121-127.

2. Greene J, Hibbard JH, Overton V. A case study of a team-based, quality-focused compensation model for primary care providers. Med Care Res Rev. 2013: 71(3):207-223.

3. Beckman H, Suchman AL, Curtin K, Greene RA. Physician reactions to quantitative individual performance reports. Am J Med Qual. 2006;21(3):192-199.

4. Wharam JF, Paasche-Orlow MK, Farber NJ, et al. High quality care and ethical pay-for-performance: a Society of General Internal Medicine policy analysis. J Gen Intern Med. 2009;24(7):854-859.

5. Thompson PD, Buchner D, Pina IL, et al; American Heart Association Council on Clinical Cardiology Subcommittee on Exercise, Rehabilitation, and Prevention; American Heart Association Council on Nutrition, Physical Activity, and Metabolism Subcommittee on Physical Activity. Exercise and physical activity in the prevention and treatment of atherosclerotic cardiovascular disease: a statement from the Council on Clinical Cardiology (Subcommittee on Exercise, Rehabilitation, and Prevention) and the Council on Nutrition, Physical Activity, and Metabolism (Subcommittee on Physical Activity). Circulation. 2003;107(24):3109-3116.

6. Di Loreto C, Fanelli C, Lucidi P, et al. Make your diabetic patients walk: long-term impact of different amounts of physical activity on type 2 diabetes. Diabetes Care. 2005;28(6):1295-1302.

7. American Association of Diabetes Educators. AADE Guidelines for the Practice of Diabetes Self-Management Education and Training (DSME/T). Diabetes Educ. 2009;35(3)(Suppl):85S-107S.

8. Informed Medical Decisions Foundation. Affordable Care Act. Available at: http://www.informedmedicaldecisions.org/shared-decisionmaking-policy/federal-legislation/affordable-care-act/. Accessed Feb 23, 2016. 
9. Mittler JN, Martsolf GR, Telenko SJ, Scanlon DP. Making sense of "consumer engagement" initiatives to improve health and health care: a conceptual framework to guide policy and practice. Milbank Q. 2013;91(1):37-77.

10. Greene J, Hibbard JH. Why does patient activation matter? An examination of the relationships between patient activation and health-related outcomes. J Gen Intern Med. 2012;27(5):520-526.

11. Nijman J, Hendriks M, Brabers A, de Jong J, Rademakers J. Patient activation and health literacy as predictors of health information use in a general sample of Dutch health care consumers. J Health Commun. 2014;19(8):955-969.

12. Smith SG, Pandit A, Rush SR, Wolf MS, Simon C. The association between patient activation and accessing online health information: results from a national survey of US adults. Health Expect. 2014;18(6):3262-3273.

13. Alegría M, Sribney W, Perez D, Laderman M, Keefe K. The role of patient activation on patient-provider communication and quality of care for US and foreign born Latino patients. J Gen Intern Med. 2009:24(Suppl 3):534-541.

14. Greene J, Hibbard JH, Sacks R, Overton V. When seeing the same physician, highly activated patients have better care experiences than less activated patients. Health Aff (Millwood). 2013;32(7): 1299-1305.

15. Hibbard JH, Greene J, Overton V. Patients with lower activation associated with higher costs; delivery systems should know their patients' 'scores'. Health Aff (Millwood). 2013;32(2):216-222.

16. Marshall R, Beach MC, Saha $S$, et al. Patient activation and improved outcomes in HIV-infected patients. J Gen Intern Med. 2013;28(5):668-674.

17. Remmers C, Hibbard J, Mosen DM, Wagenfield M, Hoye RE, Jones C. Is patient activation associated with future health outcomes and healthcare utilization among patients with diabetes? J Ambul Care Manage. 2009;32(4):320-327.

18. Begum N, Donald M, Ozolins IZ, Dower J. Hospital admissions, emergency department utilisation and patient activation for selfmanagement among people with diabetes. Diabetes Res Clin Pract. 2011;93(2):260-267.

19. Dentzer S. Rx for the 'blockbuster drug' of patient engagement. Health Aff (Millwood). 2013;32(2):202.

20. Hibbard JH, Greene J. What the evidence shows about patient activation: better health outcomes and care experiences; fewer data on costs. Health Aff (Millwood). 2013;32(2):207-214.

21. Greene J, Hibbard JH, Sacks R, Overton V, Parrotta CD. When patient activation levels change, health outcomes and costs change, too. Health Aff (Millwood). 2015;34(3):431-437.

22. Hibbard J, Greene J, Shi Y, Mittler J, Scanlon D. Taking the long view: how well do patient activation scores predict outcomes four years later? Med Care Res Rev. 2015;72(3):324-337.

23. Anderson RM, Funnell MM, Butler PM, Arnold MS, Fitzgerald JT, Feste CC. Patient empowerment. Results of a randomized controlled trial. Diabetes Care. 1995;18(7):943-949.

24. Deen D, Lu WH, Weintraub MR, Maranda MJ, Elshafey S, Gold MR. The impact of different modalities for activating patients in a community health center setting. Patient Educ Couns. 2012;89(1):178-183.

25. Maranda MJ, Deen D, Elshafey S, Herrera M, Gold MR. Response to a patient activation intervention among Spanish-speaking patients at a community health center in New York City. J Health Care Poor Underserved. 2014;25(2):591-604.

26. Lorig K, Ritter PL, Laurent DD, et al. Online diabetes self-management program: a randomized study. Diabetes Care. 2010; 33(6):1275-1281.

27. Kangovi S, Mitra N, Grande D, et al. Patient-centered community health worker intervention to improve posthospital outcomes: a randomized clinical trial. JAMA Intern Med. 2014;174(4):535-543.
28. Skolasky RL, Maggard AM, Li D, Riley LH III, Wegener ST. Health behavior change counseling in surgery for degenerative lumbar spinal stenosis. Part II: patient activation mediates the effects of health behavior change counseling on rehabilitation engagement. Arch Phys Med Rehabil. 2015;96(7):1208-1214.

29. Linden A, Butterworth S. A comprehensive hospital-based intervention to reduce readmissions for chronically ill patients: a randomized controlled trial. Am J Manag Care. 2014;20(10):783-792.

30. Lawson KL, Jonk $Y$, O'Connor H, Riise KS, Eisenberg DM, Kreitzer MJ. The impact of telephonic health coaching on health outcomes in a high-risk population. Glob Adv Health Med. 2013;2(3):40-47.

31. Hibbard JH, Greene J, Tusler M. Improving the outcomes of disease management by tailoring care to the patient's level of activation. Am J Manag Care. 2009;15(6):353-360.

32. Lundahl B, Moleni T, Burke BL, et al. Motivational interviewing in medical care settings: a systematic review and meta-analysis of randomized controlled trials. Patient Educ Couns. 2013;93(2):157-168.

33. Noordman J, van der Weijden T, van Dulmen S. Communicationrelated behavior change techniques used in face-to-face lifestyle interventions in primary care: a systematic review of the literature. Patient Educ Couns. 2012;89(2):227-244.

34. Mercer SW, Neumann M, Wirtz M, Fitzpatrick B, Vojt G. General practitioner empathy, patient enablement, and patient-reported outcomes in primary care in an area of high socio-economic deprivation in Scotland-a pilot prospective study using structural equation modeling. Patient Educ Couns. 2008;73(2):240-245.

35. Mercer SW, Jani BD, Maxwell M, Wong SYS, Watt GCM. Patient enablement requires physician empathy: a cross-sectional study of general practice consultations in areas of high and low socioeconomic deprivation in Scotland. BMC Fam Pract. 2012;13(1):6.

36. Pawlikowska T, Zhang W, Griffiths F, van Dalen J, van der Vleuten C. Verbal and non-verbal behavior of doctors and patients in primary care consultations - how this relates to patient enablement. Patient Educ Couns. 2012;86(1):70-76.

37. Schmittdiel J, Mosen DM, Glasgow RE, Hibbard J, Remmers C, Bellows J. Patient Assessment of Chronic Illness Care (PACIC) and improved patient-centered outcomes for chronic conditions. J Gen Intern Med. 2008;23(1):77-80.

38. Greene J, Yedidia MJ; Take Care to Learn Evaluation Collaborative. Provider behaviors contributing to patient self-management of chronic Illness among underserved populations. J Health Care Poor Underserved. 2005;16(4):808-824.

39. Bodenheimer $T$, Wagner EH, Grumbach K. Improving primary care for patients with chronic illness. JAMA. 2002;288(14):1775-1779.

40. Bradley EH, Curry LA, Ramanadhan S, Rowe L, Nembhard IM, Krumholz HM. Research in action: using positive deviance to improve quality of health care. Implement Sci. 2009;4(1):25.

41. Pascale R, Sternin J, Sternin M. The Power of Positive Deviance. Boston, MA: Harvard Business School Publishing; 2010.

42. Curry LA, Spatz E, Cherlin E, et al. What distinguishes topperforming hospitals in acute myocardial infarction mortality rates? A qualitative study. Ann Intern Med. 2011;154(6):384-390.

43. Landman AB, Spatz ES, Cherlin EJ, Krumholz HM, Bradley EH, Curry LA. Hospital collaboration with emergency medical services in the care of patients with acute myocardial infarction: perspectives from key hospital staff. Ann Emerg Med. 2013;61(2):185-195.

44. Taliani CA, Bricker PL, Adelman AM, Cronholm PF, Gabbay RA. Implementing effective care management in the patient-centered medical home. Am J Manag Care. 2013;19(12):957-964.

45. Gabbay RA, Friedberg MW, Miller-Day M, Cronholm PF, Adelman A, Schneider EC. A positive deviance approach to understanding key features to improving diabetes care in the medical home. Ann Fam Med. 2013;11(Suppl 1):S99-S107. 
46. Marsh DR, Schroeder DG, Dearden KA, Sternin J, Sternin M. The power of positive deviance. BMJ. 2004;329(7475):1177-1179.

47. McAllister JW, Cooley WC, Van Cleave J, Boudreau AA, Kuhlthau K. Medical home transformation in pediatric primary care-what drives change? Ann Fam Med. 2013;11(Suppl 1):S90-S98.

48. Berggren WL, Wray JD. Positive deviant behavior and nutrition education. Food Nutr Bull. 2002;23(4)(Suppl):9-10.

49. Hibbard JH, Stockard J, Mahoney ER, Tusler M. Development of the patient activation measure (PAM): conceptualizing and measuring activation in patients and consumers. Health Serv Res. 2004;39 (4 Pt 1):1005-1026.

50. Hibbard JH, Mahoney ER, Stockard J, Tusler M. Development and testing of a short form of the patient activation measure. Health Serv Res. 2005;40(6 Pt 1):1918-1930.

51. Fowles JB, Terry P, Xi M, Hibbard J, Bloom CT, Harvey L. Measuring self-management of patients' and employees' health: further validation of the patient activation measure (PAM) based on its relation to employee characteristics. Patient Educ Couns. 2009;77(1):116-122.

52. Brown JB, Harris SB, Webster-Bogaert S, Wetmore S, Faulds C, Stewart M. The role of patient, physician and systemic factors in the management of type 2 diabetes mellitus. Fam Pract. 2002; 19(4):344-349.

53. Damschroder LJ, Lutes LD, Kirsh S, et al. Small-changes obesity treatment among veterans: 12 -month outcomes. Am J Prev Med. 2014;47(5):541-553
54. Bennett WL, Gudzune KA, Appel LJ, Clark JM. Insights from the POWER practice-based weight loss trial: a focus group study on the PCP's role in weight management. J Gen Intern Med. 2014; 29(1):50-58.

55. Aschner P, LaSalle J, McGill M; Global Partnership for Effective Diabetes Management. The team approach to diabetes management: partnering with patients. Int J Clin Pract Suppl. 2007;(157):22-30.

56. Dixon A, Hibbard J, Tusler M. How do people with different levels of activation self-manage their chronic conditions? Patient. 2009;2(4):257-268.

57. Pollak KI, Alexander SC, Coffman CJ, et al. Physician communication techniques and weight loss in adults: Project CHAT. Am J Prev Med. 2010;39(4):321-328.

58. Snowden AM, Vetta E, Mlodzik R, LaFrance A, Xiong M, Bachmann S. MN Community Measurement: 2013 Health Care Quality Report. Compare Clinic, Medical Group and Hospital Performance. Minneapolis, MN; MN Community Measurement; 2013.

59. Anderson RM, Funnell MM. Patient empowerment: reflections on the challenge of fostering the adoption of a new paradigm. Patient Educ Couns. 2005;57(2):153-157.

60. Funnell MM, Anderson RM. Empowerment and self-management of diabetes. Clin Diabetes. 2004;22(3):123-127. 